Editorial

\title{
New Research on Housing and Territorial Stigma: Introduction to the Thematic Issue
}

\author{
Peer Smets ${ }^{1, *}$ and Margarethe Kusenbach ${ }^{2}$ \\ ${ }^{1}$ Department of Sociology, Vrije Universiteit Amsterdam, 1081 HV Amsterdam, The Netherlands; \\ E-Mail: p.g.s.m.smets@vu.nl \\ 2 Department of Sociology, University of South Florida, Tampa, FL 33620, USA; E-Mail: mkusenba@usf.edu \\ * Corresponding author
}

Submitted: 17 February 2020 | Published: 27 February 2020

\begin{abstract}
This introduction to the thematic issue on housing and territorial stigma provides concise overviews of the concepts of stigma, housing stigma, and territorial (or neighborhood) stigma, while tracing back current research on these topics to the pioneering work of Erving Goffman and Loic Wacquant. In doing this, we place particular attention on social responses to, and coping strategies with, stigma, especially various forms of stigma resistance. Finally, in brief summaries of all articles in the thematic issue, we emphasize their shared themes and concerns.
\end{abstract}

\section{Keywords}

Goffman; homelessness; housing; marginalization; migration; neighborhoods; social/public housing; stigma; territorial stigmatization; Wacquant

\section{Issue}

This editorial is part of the issue "New Research on Housing and Territorial Stigma" edited by Margarethe Kusenbach (University of South Florida, USA) and Peer Smets (Vrije Universiteit Amsterdam, The Netherlands).

(C) 2020 by the authors; licensee Cogitatio (Lisbon, Portugal). This article is licensed under a Creative Commons Attribution 4.0 International License (CC BY).

\section{Introduction}

It is the goal of this thematic issue to present new and original research on experiences and social processes of stigmatization in relation to housing and neighborhoods - as applied, for instance, to people living in public or social housing developments, institutional housing, impoverished neighborhoods, or informal settlements, yet also to those without any housing, as well as migrants and displaced groups. Residents of so-called "problem" neighborhoods and other marginalized locations typically experience multiple forms of denigration that may include cultural stigmatization, physical and symbolic exclusion from public spaces and institutions, extreme surveillance, biased policing and criminalization, material neglect, as well as exposure to violence, crime, disorder, and environmental hazards. People in marginalized neighborhoods and housing arrangements are tainted by virtue of living or spending time in these environments. They face personal and collective stigmatization by others based on being considered uneducated, lazy, dirty, immoral, or criminal. Housing and territorial stigma is seldom rooted in personal familiarity and in-depth understanding, yet it most often stems from second-hand stereotypes and false characterizations that circulate in mass media and popular culture.

To give one example: The visibility of rubbish or trash on the streets of disadvantaged neighborhoods is often interpreted as evidence for the poor cleanliness practices and preferences of their inhabitants. When these residents are migrants from other, and especially non-Western, countries, judgements are typically associated with the migrants' "inferior" cultural or ethnic backgrounds or religious beliefs (Douglas, 2003). In the 2019 Dutch documentary film Returning to Akbar Street (van Erp, Busman, \& Dogan, 2019), about a street in the 
disadvantaged "Kolenkit" neighborhood in Amsterdam, anthropologist Sinan Çankaya offers an alternative and more accurate view of this problem. His insights are based on his personal life and research in the neighborhood where large migrant families from non-Western countries live in small housing units, replacing wealthier, white residents who moved out when migrants began to arrive. Here, apartments and neighborhood facilities were originally created for smaller households and a smaller number of residents overall. For instance, the size and number of trash containers is simply too small to hold the amount of rubbish produced by current residents, and garbage pick-up is too infrequent, leading to trash spilling out into the streets on a regular basis. Poverty and cultural barriers are keeping residents from furnishing their own solutions. Due to a lack of facilities and official responses, the neighborhood trash problem is spiraling out of control. To outsiders, it looks like the new migrant residents are to blame for the issue and, moreover, that it is their cultural or personal preference to live on dirty streets, yet this interpretation is false and based on stereotypes. As this example shows, normative cultural views of places, objects, practices, and moral character become conflated and reinforce each other over time.

\section{What Is Stigma?}

The example indicates that housing and territorial stigma is a complex phenomenon which can be difficult to define and apply precisely in scholarly research. In this section, we approach the topic of housing and territorial stigma via a brief discussion of stigma more generally. One useful definition of stigma is offered by Pescosolido and Martin (2015, p. 91) in a thorough overview article:

Stigma...is the mark, the condition, or status that is subject to devaluation....Stigmatization is the social process by which the mark affects the lives of all those touched by it.

Here, we see that stigma, as a noun, is a negative attribute that is associated with certain people, places, or objects. In contrast, stigmatization, as a verb, refers to a social process by which persons suffer negative impacts due to their association with a condition. This process can include a variety of actions, such as labeling, stereotyping, discrimination, exclusion, and separation, among others. Stigmatization is rooted in cultural beliefs; however, it also depends on power and social structures. It can only occur when some have the ability to impose their definitions and treatments on others due to their privileged access to material and immaterial resources. Interestingly, through contamination, stigmatization can also affect people who are merely connected with stigmatized others, places, or objects but are not themselves carriers of the mark (for a more detailed overview of the concept see, in this volume, Horgan, 2020; see also Link \& Phelan, 2001).
In their overview, Bos, Pryor, Reeder, and Stutterheim (2013) offer a useful and innovative typology of stigma. The authors distinguish between public stigma, self-stigma, stigma by association, and structural stigma. The concept of "public stigma" aims at those who engage in stigmatizing others based on negative perceptions and interpretations. Here, cognitive, affective, and behavioral aspects of stigma and stigmatization are examined together. The second type of stigma, "self-stigma," aims to conceptualize the social and psychological impacts that processes of stigmatization have on stigma recipients. Third, "stigma by association" can be defined as "social and psychological reactions to people associated with a stigmatized person (e.g., family and friends) as well as people's reactions to being associated with a stigmatized person" (Bos et al., 2013, p. 2). Finally, "structural stigma" refers to how societal institutions and ideologies legitimize and cement a person or group's stigmatized status. We find this typology helpful in that it differentiates the major actors and components that define stigma as a social problem and topic of scholarly analysis.

We would be remiss to gloss over the pioneering work on stigma by Erving Goffman (1963), in which stigma was primarily linked with the social construction of deviance. In Goffman's understanding, stigma is negative moral judgment that is attached to people, and their associates, based on either a physical attribute, group membership, or particulars of their character or behavior. Goffman's introduction of stigma as a topic of sociological concern has inspired a large body of research on various forms of social stigmatization in relation to many topics (for overviews see Link \& Phelan, 2001; Pescosolido \& Martin, 2015; Tyler \& Slater, 2018). Current issues discussed in the vast stigma literature include, for example, racialized poverty (Loyd \& Bonds, 2018), mental illness (Sheehan, Nieweglowski, \& Corrigan, 2017), gender and disability (Thomas, 1999), sanitation work (Vázquez, 2016), and sex work (Benoit et al., 2018). Today's multifaceted stigma research has generated a variety of concepts and models that are rooted in both social constructionism and critical theories of social inequalities. The same can be observed regarding the particular issue of housing and territorial stigma.

\section{Housing and Territorial Stigma}

As fundamental as they are, Goffman's ideas focus on stigma in reference to people and not with respect to places. While he recognized the importance of bodily stigma, he did not discuss spatial locations, neighborhoods, and forms of housing as material sources of stigma and stigmatization. It is the merit of Loic Wacquant $(2007,2008)$ and his collaborators (Wacquant, Slater, \& Pereira, 2014) that the attention of stigma scholars has expanded to places and neighborhoods, particularly those inhabited by poor residents of color in urban areas. He was also a pioneer in promoting comparative 
stigma research in multiple locations, especially across national boundaries.

Theoretically, Wacquant (2008) draws on Bourdieu's concept of symbolic power that is used to examine the making and unmaking of social groups and their spaces from a top down perspective. Besides focusing on the production and institutionalization of stigma, Wacquant's work makes claims about the negative social, material, and emotional impacts of stigma that is linked to the built environment. He argues that internalized territorial stigma leads to declining mutual solidarity, increasing social fragmentation, diminishing institutional support, and lacking economic opportunities (Wacquant et al., 2014). Building on Goffman's and Wacquant's earlier work, territorial stigma in neighborhoods has been studied widely and internationally by a diverse community of scholars (for instance, to name just a few, on Amsterdam, Pinkster, Ferier, \& Hoekstra, 2020; on London, le Grand, 2014; on New Delhi, Ganguly, 2018; and on Milwaukee, Wisconsin, Loyd \& Bonds, 2018).

Most current research on territorial stigma does not differentiate between stigma that is applied to neighborhoods, types of housing, and types of tenure-however, making such distinctions is becoming increasingly important to further broaden and strengthen this area of research in the future. While housing has a prominent place in the literature dealing with territorial stigma, the focus is placed on those living in public or social housing developments that are owned and managed by municipal, state, or national government entities (e.g., Watt \& Smets, 2017). However, there are other forms of housing, as well as other forms of tenure, that are also stigmatized and will also need consideration: for instance, barrio, favela or "slum" dwellings (Bredenoord, van Lindert, \& Smets, 2014; Ferguson \& Smets, 2010), manufactures housing and mobile homes (Kusenbach, 2009), Single Room Occupancy (SRO) residences (Horgan, 2018), and, in some contexts, even privately rented homes and apartments (Vassenden \& Lie, 2013).

Since not all forms of housing and tenure stigmatization are tied to neighborhoods and/or territories, we need to deepen our understanding of where and how housing and tenure intersect with more generic aspects of the process of stigmatization. Horgan's theoretical article offers significant steps into this direction:

Housing stigmatization...is neither monolithic nor unidirectional. Thus, a general theory must account for unit-dweller and unit-neighbourhood relationships, as well as multiple housing types and forms of tenure. (Horgan, 2020, p. 13)

Housing and tenure stigma are difficult to grasp because, in almost all cases, they interact with other kinds of stigma, typically regarding territory/neighborhood, but also based on individual or group characteristics in terms of class, race/ethnicity, heritage, religion, health/disability, age, gender, and/or sexuality (for exam- ples see Elias \& Scotson, 1994; Smets \& Sneep, 2017). Moreover, there is often a general distrust among established residents toward newcomers, regardless of who they are. Note that, depending on contexts, surrounding attributes can intensify housing stigma yet may sometimes work to reduce or even overcome housing stigma.

Despite some research efforts, the multiple layers and aspects of stigmatization (housing, tenure, neighborhood, etc.) intersect in ways that we have yet to examine and understand in sufficient depth. Remedying other thinly covered topics in the literature would require new investigations of housing and territorial stigma in non-metropolitan (suburban, rural) locations, the Global South, among middle classes and higher income groups, to mention only a few. Generally speaking, we believe that housing and territorial stigma is a rapidly growing and diversifying area of research that will continue to be influenced by dominant theories and evolving concerns in sociology and neighboring disciplines.

\section{Stigma Responses and Resistance}

Over the past two decades, one growing thematic focus in the literature on housing and territorial stigmabesides the social production of stigma by powerful actors, including the state-are the experiences and behavioral responses of stigma recipients. Evidence from numerous studies shows that their reactions vary greatly and can be located on a continuum unfolding between two extremes: acceptance/internalization of, and resignation to, the inflicted stigma on the one side (Wacquant, 2007,2008 ) and rejection of, and resistance to, stigma and stigmatization on the other (see, for instance, Hastings, 2004; Jensen \& Christensen, 2012; Kirkness, 2014; Kusenbach, 2009; Palmer, Ziersch, Arthurson, \& Baum, 2007).

In their research on American and French public housing neighborhoods, Wacquant (2008) and his colleagues, as well as scholars working in their wake, have observe that residents of denigrated neighborhoods internalize stigma and become demoralized as a result. It is argued that resigned acceptance and incorporation of negative views lowers residents' self-esteem, triggers a self-fulfilling prophecy, and eventually perpetuates and even strengthens the validity of stigma in the eyes of nonresidents and public institutions. Marginalized neighborhoods are characterized by a lack of informal support and negative symbolic capital (see Watt, 2006). Residents face discrimination on the labor market and differential treatment from governmental institutions. In other words, residents become trapped in stigmatized spaces and are unable to escape, leading to further alienation and exclusion from mainstream society. This is the selfperpetuating cycle of exclusion, in which stigmatization, internalization, alienation, and isolation are stages that reinforce each other (Wacquant et al., 2014).

While Wacquant's and his colleagues' groundbreaking contributions to the study of neighborhood or ter- 
ritorial stigma are beyond any doubt, the evolving literature includes an increasing number of studies that offer more nuanced, and at times contradicting, accounts of the impacts of stigmatization on affected residents and their adaptive responses. Many studies reveal that a certain degree of stigma acceptance and internalization can, indeed, be observed among some residents of denigrated housing types or neighborhoods. However, other, typically the majority of, residents engage in individual and collective strategies that resist and counter the stigma they experience, based on the conviction that these views are incorrect and that they, as individuals or as a community, deserve better.

For instance, Palmer et al. (2007) examine how residents deal with reputational problems of the neighborhood. First, they draw boundaries between "good" and "bad" parts and associate themselves with the better area. A second strategy of resistance lies in stigmatized residents' engagement in local social and civic activities. Lastly, residents challenge external stereotypes through getting involved in conversation and public discourse aimed at fighting negative labels. Others studies on social housing estates in the United Kingdom focus on residents' collective efforts to combat negative views through image management (Dean \& Hastings, 2000; Hastings, 2004; see also Wassenberg, 2004).

With varying emphasis, all articles collected in this thematic issue build on both Goffman's pioneering introduction of stigma to social science discourse and Wacquant's pivotal theorizing and research on territorial stigmatization. Likewise, in one form or another, all articles in this thematic issue discuss reactions to stigma and examine coping strategies among study participants, while placing particular emphasis on various forms of resistance at both individual and collective levels. In our view, besides strengthening the theoretical foundation of the field, the nuanced empirical analyses of stigma resistance across diverse social and geographical locations are this issue's most significant contribution to the growing literature on housing and territorial stigma.

\section{Overview of Articles}

This thematic issue originated in a session titled "Housing Stigma" co-organized by the editors of this volume for the 19th World Congress of the International Sociological Association, in Toronto, July 2018, for Research Committee 21 "Regional and Urban Development." Four of the seven articles present research conducted in Western Europe (including in Finland, England, and Scotland), two articles report on North America (United States and Canada), and one article examines housing stigmatization in Asia (Bangladesh). All articles are based on qualitative research, including various kinds of ethnographic observation, in-depth interviews, as well as secondary media and historical research. Some articles offer case studies of single neighborhoods or sites, while others provide a composite analysis based on research in two or more locations; only one article employs a comparative analytic framework. In this final section, we conclude the introduction by offering brief overviews of all seven articles in this thematic issue.

Mervyn Horgan's (2020) groundbreaking article delivers a much-needed theoretical clarification of the concept of housing stigma. After describing the broader social-structural contexts and existing previous knowledge concerning housing stigmatization and related topics, Horgan describes seven elements of a general theory of housing stigma-identifying it as relational, contextual, processual, reinforceable, reversible, morally loaded, and contagious-all of which are revisited, in one form or another, in the following empirical articles. Going beyond its theoretical contribution, Horgan's article also includes a vignette from his own research on the stigmatization of SRO residents in a wealthy Toronto neighborhood, a housing type that has been understudied in the past.

Housing and territorial stigma can only be understood if they are viewed in relation to broader historical, social, and material contexts. In his article about a social housing estate in the periphery of London, United Kingdom, Paul Watt (2020) relates residents' responses to stigma to their struggles in coping with dilapidated housing conditions, an aspect of the built environment that is often overlooked in stigma research. Through an analysis of qualitative interviews and other data sources, Watt finds that the latter, material circumstances are often much more challenging, and impact residents' daily lives more significantly, when compared with symbolic stigmatization. Watt argues that, while serious, symbolic denigrations are often eclipsed by more forceful, in this case material, challenges that affect residents' lives, and that attention to build environments is critical in this area of study.

Attending to a different kind of context, in his article, Pekka Tuominen (2020) closely examines the history, as well as the changing reputation and representation over time, of a socially stigmatized neighborhood near Helsinki in Finland through long-term ethnographic and media research. It is here where specific "senses of belonging and exclusion" are anchored that give rise to particular practices, strategies, and narratives in response to stigma that were provided by diverse residents, both individually and collectively (Tuominen, 2020, p. 34). Shared stigma, when it is not internalized, can empower residents and lead to a strong sense of belonging grounded in shared resistance. Tuominen shows how his research participants were united in their efforts to resist the territorial stigma and turn their place of living into a positive feature of their identity by drawing on Herzfeld's concept of cultural intimacy.

Also relying on historic and long-term ethnographic research conducted in Finland, in her article, Lotta Junnilainen (2020) reconstructs two alternative stigma narratives that she found at the collective level among residents of two Finnish social housing neighborhoods: 
one rooted in "class struggle" and the other in "middleclass aspiration," as sources of residential identity, dignity, and pride. In her view, housing and territorial stigma can only be understood if it is viewed in relation to the history and place-based stories of specific locations, and in relation to other, non-stigmatizing social identities and characteristics of its targets. It is here where specific "cultural milieus" are rooted that give rise to particular practices, strategies, and narratives in relation to housing stigma that were observed among diverse residents, both individually and collectively, and by employing a comparative analytic framework.

The final three articles offer detailed examinations of how residents in various locations respond to the negative reputation and stigmatization of their neighborhoods. In their article which is mainly based on interview research, Kazil Fattah and Peter Walters (2020) provide valuable insights into housing and territorial stigmatization in the Global South in their analysis of "discursive formations." They found that residents in two poor and denigrated neighborhoods in Dhaka, Bangladesh, reject the stigma aimed at their place of living and produce counternarratives, even though some appear to readily stigmatize residents of other neighborhoods. Dhaka informants rallied together in declaring their own neighborhoods to be "good places" to live for the poor, due to the many advantages and resources they provide. Fattah and Walter's article reveals interesting similarities yet also differences with housing and territorial stigmatization in the Global North that will have to be examined elsewhere in more detail in the future.

Focusing on an understudied housing type, in her article, Margarethe Kusenbach (2020) examines reactions to housing stigmatization in mobile home communities in Florida, in the United States. Her analysis discusses three major response strategies found among poor white mobile home residents, the most vulnerable targets of the "trailer trash" stigma, which is simultaneously aimed at certain neighborhoods, a form of housing, and residents' personal character. The three identified response strategies are resisting, downplaying, and perpetuating, the latter showing some acceptance of the stigma when it is rejected personally but used to stigmatize others who live nearby. The different reactions to stigma are related to varying senses of belonging and unbelonging in the mobile home community. By examining white, non-urban recipients of housing stigma who are predominantly homeowners, Kusenbach's article broadens research on this topic beyond urban populations of color who reside in public housing complexes or inner-city neighborhoods.

Lastly, in her article, Jennifer Hoolachan (2020) circles back to examining how housing stigma is embedded within larger contexts by including study participants' other identities based on (young) age and deviant behavior (in this case, drug use) in the analysis. Hoolachan's ethnographic and interview-based research with homeless youth took place in a transitional housing facility in Scotland. Echoing findings of other articles in this issue, she discovered that youth engage in distancing and othering by projecting the stigma that was aimed at them onto others, as well as rejecting stigma altogether, and producing alternative, positive counternarratives. Hoolachan shows how multiple social identities work together, how they can be variably constructed as either positive or negative, and consequently, how they are either embraced or rejected. Hoolachan's analysis opens up new links between housing stigmatization research and the vast literatures on homelessness, youth, and deviance, as well as work on identity construction and management more generally.

\section{Conflict of Interests}

The authors declare no conflict of interests.

\section{References}

Benoit, C., Smith, M., Jansson, M., Magnus, S., Flagg, J., \& Maurice, R. (2018). Sex work and three dimensions of self-esteem: Self-worth, authenticity and self-efficacy. Culture, Health \& Sexuality, 20(1), 69-83.

Bos, A. E. R., Pryor, J. B., Reeder, G. D., \& Stutterheim, S. E. (2013). Stigma: Advances in theory and research. Basic and Applied Social Psychology, 35(1), 1-9.

Bredenoord, J., van Lindert, P., \& Smets, P. (2014). Affordable housing in the global south: Seeking sustainable solutions. London: Routledge and Earthscan.

Dean, J., \& Hastings, A. (2000). Challenging images. Housing estates, stigma and regeneration. Bristol: The Policy Press.

Douglas, M. (2003). Purity and danger: An analysis of concept of pollution and taboo. London: Routledge.

Elias, N., \& Scotson, J. L. (1994). The established and the outsiders. London: Sage.

Fattah, K. N., \& Walters, P. (2020). "A good place for the poor!" Counternarratives to territorial stigmatisation from two informal settlements in Dhaka. Social Inclusion, 8(1), 55-65.

Ferguson, B., \& Smets, P. (2010). Finance for incremental housing: Current status and prospects for expansion. Habitat International, 34(3), 288-298.

Ganguly, S. (2018). Socio-spatial stigma and segregation: A Balmiki colony in Central Delhi. Economic and Political Weekly, 53(50), 50-57.

Goffman, E. (1963). Stigma: Notes on the management of spoiled identity. New York, NY: Simon \& Schuster.

le Grand, E. (2014). Class, community and belonging in a 'Çhav Town.' In P. Watt \& P. Smets (Eds.), Mobilities and neighbourhood belonging in cities and suburbs (pp. 164-181). New York, NY: Palgrave Macmillan.

Hastings, A. (2004). Stigma and social housing estates: Beyond pathological explanations. Journal of Housing and the Built Environment, 19(3), 233-254.

Horgan, M. (2018). Territorial stigmatization and territo- 
rial destigmatization: A cultural sociology of symbolic strategy in the gentrification of Parkdale (Toronto). International Journal of Urban and Regional Research, 42(3), 500-516.

Horgan, M. (2020). Housing stigmatization: A general theory. Social Inclusion, 8(1), 8-19.

Hoolachan, J. (2020). Exploring the 'spoiled' and 'celebrated' identities of young and homeless drug users. Social Inclusion, 8(1), 76-85.

Jensen, S. Q., \& Christensen, A. (2012). Territorial stigmatization and local belonging: A study of the Danish neighbourhood Aalborg East. City, 16(1/2), 74-92.

Junnilainen, L. (2020). Place narratives and the experience of class: Comparing collective destigmatization strategies in two social housing neighborhoods. Social Inclusion, 8(1), 44-54.

Kirkness, P. (2014). The cités strike back: Restive responses to territorial taint in the French banlieues. Environment and Planning A: Economy and Space, 46(6), 1281-1296.

Kusenbach, M. (2009). Salvaging decency: Mobile home residents' strategies of managing the stigma of 'trailer living.' Qualitative Sociology, 32(4), 399-428.

Kusenbach, M. (2020). "Trailer trash" stigma and belonging in Florida mobile home parks. Social Inclusion, 8(1), 66-75.

Link, B. G., \& Phelan, J. C. (2001). Conceptualizing stigma. Annual Review of Sociology, 27, 363-385.

Loyd, J. M., \& Bonds, A. (2018). Where do black lives matter? Race stigma, and place in Milwaukee, Wisconsin. The Sociological Review Monographs, 66(4), 898-918.

Palmer, C., Ziersch, A., Arthurson, K., \& Baum, F. (2007). Challenging the stigma of public housing: Preliminary findings from a qualitative study in South Australia. Urban Policy and Research, 22(4), 411-426.

Pescosolido, B. A., \& Martin, J. K. (2015). The stigma complex. Annual Review of Sociology, 41, 87-116.

Pinkster, F. M., Ferier, M. S., \& Hoekstra, M. S. (2020). On the stickiness of territorial stigma: Diverging experiences in Amsterdam's most notorious neighbourhood. Antipode, 52(2), 522-541.

Sheehan, L., Nieweglowski, K., \& Corrigan, P. W. (2017). Structures and types of stigma. In W. Gaebel, W. Roessler, \& N. Sartorius (Eds.), The stigma of mental illness-End of the story? (pp. 43-66). Berlin: Springer.

Smets, P., \& Sneep, K. (2017). Tenure mix: Apart or to- gether? Homemaking practices and belonging in a Dutch street. Journal of Housing and the Built Environment, 32(1), 91-106.

Thomas, C. (1999). Female forms: Experiencing and understanding disability. Buckingham: Open University Press.

Tuominen, P. (2020). Historical and spatial layers of cultural intimacy: Urban transformation of a stigmatised suburban estate on the periphery of Helsinki. Social Inclusion, 8(1), 34-43.

Tyler, I., \& Slater, T. (2018). Rethinking the sociology of stigma. The Sociology Review Monographs, 66(4), 721-743.

van Erp, M., Busman, M. (Producers), \& Dogan, G. (Director). (2019). Terug naar de Akbarstraat [Returning to Akbar Street; Documentary Film]. The Netherlands: De Familie Film \& TV.

Vassenden, A., \& Lie, T. (2013). Telling others how you live: Refining Goffman's stigma theory through an analysis of housing struggles in a homeowner nation. Symbolic Interaction, 36(1), 78-98.

Vázquez, J. J. (2016). The stigma of making a living from garbage: Meta-sterotypes of trash-pickers in León (Nicaragua). Scandinavian Journal of Psychology, 57(3), 122-128.

Wacquant, L. (2007). Territorial stigmatization in the age of advantaged marginality. Thesis Eleven, 91(1), 66-77.

Wacquant, L. (2008). Urban outcasts: A comparative sociology of advanced marginality. Cambridge: Polity.

Wacquant, L., Slater, T., \& Pereira, V. B. (2014). Territorial stigmatization in action. Environment and Planning $A$, 46(6), 1270-1280.

Wassenberg, F. (2004). Renewing stigmatized estates in the Netherlands: A framework for image renewal strategies. Journal of Housing and the Built Environment, 19(3), 271-292.

Watt, P. (2006). Respectability, roughness and 'race': Neighbourhood place images and the making of working-class social distinctions in London. International Journal of Urban and Regional Research, 30(4), 776-797.

Watt, P. (2020). Territorial stigmatisation and poor housing at a London 'sink estate.' Social Inclusion, 8(1), 20-33.

Watt, P., \& Smets, P. (2017). Social housing and urban renewal: A cross national perspective. Bingley: Emerald.

\section{About the Authors}

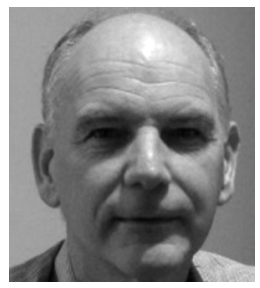

Peer Smets (PhD) is employed at the Department of Sociology, Vrije Universiteit Amsterdam. His research mainly focuses on urban habitat conditions (housing and its living environment) in low-income neighborhoods in southern and western countries. Attention is also paid to perceptions which determine its livability. He has published on urban segregation, housing, housing finance, government bureaucracy, and social life in neighborhoods. His current research focuses on urban commons. 
Margarethe Kusenbach is Associate Professor in the Department of Sociology at the University of South Florida, Tampa, USA. Her research interests and areas of publication include urban and community sociology, social psychology (identity and emotions), disasters and environment, and qualitative methods. For the past several years, her work has focused on issues of home and belonging among mobile home residents and lifestyle migrants, however, her current research focuses on the role of street art and artists in urban development. 